\title{
THE ANNUAL MEETING IN CLEVELAND
}

The thirty-seventh Annual Meeting of the American Mathematical Society was held at Cleveland, Ohio, from Monday to Wednesday, December 29-31, 1930. The meeting opened on Monday afternoon with a joint session of the Society, the American Statistical Association, and Sections A and K of the American Association for the Advancement of Science. The Council met at the Hotel Statler on December 30 and 31. Since there was no quorum of the Board of Trustees at the meeting called for December 29, there was an adjourned meeting in New York City on January 2. The scientific sessions were held in the building of the School of Education of the Western Reserve University. Tuesday and Wednesday mornings were devoted to sectional sessions of the Society, and on Tuesday afternoon there was a general session to hear an address by Professor G. D. Birkhoff on Poincaré's Last geometric theorem, its generalizations and dynamical applications. Later in the afternoon the eighth Josiah Willard Gibbs Lecture under the joint auspices of the Society and the American Association for the Advancement of Science was delivered by Professor Edwin Bidwell Wilson. His address was entitled Reminiscences of Gibbs by a student and colleague. On Wednesday afternoon there was a joint meeting of Section A of the American Association for the Advancement of Science, the Mathematical Association of America, and the Society, at which Professor E. T. Bell gave his retiring address as chairman of Section A on Mathematics and speculation. Professor Oystein Ore spoke on Recent developments in abstract algebra and Professor Karl Menger on Axiomatic theory of dimension. At the dinner on Wednesday evening at the Hotel Statler, Professor E. R. Hedrick was toastmaster, and speeches were delivered by Professor J. W. Young, Professor E. T. Bell, and President Eisenhart. A unanimous vote was passed thanking the Presidents and Boards of Trustees of Western Reserve University and the Case School of Applied Science, Dean T. M. Focke, Professor W. G. Simon, and others who had contributed to the success of the local arrangements for this meeting.

The attendance included the following two hundred twenty members: 
C. R. Adams, R. P. Agnew, O. P. Akers, J. W. Alexander, E. S. Allen, Mildred Allen, R. B. Allen, N. L. Anderson, R. C. Archibald, C. S. Atchison, W. L. Ayres, R. W. Babcock, C. L. Bacon, G. M. Bareis, I. A. Barnett, Walter Bartky, M. A. Basoco, W. D. Baten, Samuel Beatty, E. T. Bell, H. A. Bender, Theodore Bennett, T. C. Benton, H. R. Beveridge, G. D. Birkhoff, Henry Blumberg, M. G. Boyce, J. B. Brandeberry, R. W. Brink, O. E. Brown, R. S. Burington, W. D. Cairns, B. H. Camp, C. C. Camp, G. A. Campbell, R. D. Carmichael, W. M. Carruth, W. B. Carver, Jacques Chapelon, E. W. Chittenden, E. H. Clarke, A. B. Coble, A. Cohen, J. T. Colpitts, A. H. Copeland, E. B. Cowley, W. H. Cramblet, C. M. Cramlet, A. R. Crathorne, C. H. Currier, H. B. Curry, D. R. Curtiss, E. H. Cutler, Wayne Dancer, Tobias Dantzig, L. A. V. DeCleene, E. L. Dodd, H. L. Dorwart, B. F. Dostal, P. S. Dwyer, L. A. Dye, P. D. Edwards, L. P. Eisenhart, J. D. Elder, G. C. Evans, Peter Field, B. F. Finkel, Arne Fisher, W. W. Flexner, T. M. Focke, F. A. Foraker, W. B. Ford, Tomlinson Fort, R. A. K. Frisch, T. C. Fry, W. M. Gafafer, J. J. Gergen, F. J. Gerst, R. E. Gilman, J. W. Glover, L. M. Graves, L. W. Griffiths, V. G. Grove, Harris Hancock, W. L. Hart, C. B. Hennel, E. R. Hedrick, D. M. Hickey, H. C. Hicks, E. H. Hildebrandt, T. H. Hildebrandt, Einar Hille, E. J. Hirschler, B. P. Hoover, H. M. Hosford, Harold Hotelling, J. C. Hughes, W. A. Hurwitz, C. A. Hutchinson, Louis Ingold, M. H. Ingraham, Dunham Jackson, R. P. Johnson, F. E. Johnston, L. S. Johnston, F. C. Jonah, B. W. Jones, A. E. Kennelly, B. F. Kimball, H. W. Kuhn, K. W. Lamson, E. P. Lane, Lincoln LaPaz, G. A. Larew, H. D. Larsen, C. G. Latimer, D. H. Leavens, Solomon Lefschetz, A. D. Lewis, F. P. Lewis, Marie Litzinger, W. R. Longley, Dorothy McCoy, N. H. McCoy, E. J. McShane, W. D. MacMillan, W. O. Menge, Karl Menger, G. M. Merriman, W. M. Miller, E. C. Molina, C. N. Moore, R. L. Moore, T. W. Moore, W. L. Moore, J. C. Morehead, C. C. Morris, Max Morris, Paul Muehlman, F. D. Murnaghan, J. R. Musselman, J. H. Neelley, J. A. Nyswander, E. G. Olds, H. L. Olson, Oystein Ore, F. W. Owens, H. D. Owens, L. J. Paradiso, R. S. Park, B. C. Patterson, H. H. Pixley, L. C. Plant, T. M. Putnam, G. Y. Rainich, Tibor Radó, S. E. Rasor, T. H. Rawles, S. W. Reaves, M. S. Rees, W. T. Reid, C. N. Reynolds, Jr., C. E. Rhodes, R. G. D. Richardson, P. R. Rider, H. L. Rietz, H. P. Robertson, C. F. Roos, S. A. Rowland, L. L. Runge, George Sauté, H. E. Schoonmaker, G. T. Sellew, F. R. Sharpe, H. C. Shaub, W. F. Shenton, L. S. Shively, C. A. Shook, Grace Shover, W. G. Simon, L. G. Simons, H. E. Slaught, L. L. Smail, T. L. Smith, A. E. Staniland, Guy Stevenson, K. D. Swartzel, P. M. Swingle, J. L. Synge, J. D. Tamarkin, J. H. Taylor, J. S. Taylor, C. F. Thomas, J. M. Thomas, M. O. Tripp, B. M. Turner, H. W. Tyler, M. E. G. Waddell, W. J. Wagner, G. W. Walker, J. H. Weaver, F. M. Weida, M. J. Weiss, Willis Whited, J. H. C. Whitehead, E. A. Whitman, G. T. Whyburn, D. V. Widder, Norbert Wiener, R. L. Wilder, K. P. Williams, W. L. G. Williams, C. O. Williamson, E. B. Wilson, F. L. Wren, Kathryn Wyant, B. F. Yanney, C. H. Yeaton, Jacob Yerushalmy, J. W. Young.

The following sixteen persons were elected to membership in the Society: 
Professor William Ernest Fred Appuhn, Stevens Institute;

Mr. Kenneth E. Bisshopp, Beloit, Wisconsin;

Mr. Archie Blake, Chicago;

Mr. Hendrik Wade Bode, Bell Telephone Laboratories, New York;

Professor Arley T. Curlee, Salem College;

Mr. Robert L. Dietzold, Bell Telephone Laboratories, New York;

Mr. Bion Hubbard Francis, Bell Telephone Laboratories, New York;

Dr. Jakob Kevitzki, Yale University;

Professor Karl Menger, University of Vienna;

Dr. George Colin Munro, University of Buffalo;

Professor Tibor Radó, Ohio State University;

Mr. William Sell, University of Alabama;

Mr. George Richard Trott, Alabama Polytechnic Institute;

Miss Helen Martha Wright, Columbia University.

As Nominee of Members of the Department of Mathematics of Brown University: Mr. Max Astrachan;

As Nominee of the Missouri State Life Insurance Company: Mr. E. L. Faith;

The Secretary announced that the following members of the London Mathematical Society had entered the Society under the reciprocity agreement.

Dr. Lancelot Stephen Bosanquet, Lecturer in Mathematics, University College, London, England;

Professor Peter Fraser, University of Bristol, Bristol, England.

The ordinary membership in the Society is now 1,926, including 136 nominees of sustaining members and 83 life members. There are also 29 sustaining members. The total attendance of members at all meetings in 1931 was 953 ; the number of papers read was 386 . The number of members attending at least one meeting was 638 . The vote for the election of officers closed at the annual business meeting on December 31. There were 284 votes cast and the following officers were elected:

President, Professor L. P. Eisenhart.

Vice-President, Professor W. A. Manning.

Associate Secretary, Professor Tomlinson Fort.

Member of the Editorial Committee of the Bulletin, Professor E. R. Hedrick.

Member of the Editorial Committee of the Transactions, Professor R. D. Carmichael.

Member of the Editorial Committee of the Colloquium Publications, Professor E. T. Bell.

Member of the Editorial Committee of the American Journal of Mathematics, Professor G. C. Evans. 
Members of the Council, Professors Marston Morse, James Pierpont, J. D. Tamarkin, K. P. Williams, W. A. Wilson, to serve three years; Professor Warren Weaver, to serve two years.

Members of the Board of Trustees, Professors L. P. Eisenhart, W. B. Fite, Mr. Robert Henderson, Professors G. W. Mullins, and R. G. D. Richardson, to serve two years.

The reports of the Treasurer and of the auditors (Professor H. W. Reddick and Mr. J. J. Tanzola) showed a balance of $\$ 4,594.27$, exclusive of the balances in the Bulletin, Transactions, Colloquium, Journal, Library, and special funds, and of the life membership reserve. The Society's Endowment Fund, of par value $\$ 76,000.00$, yielded for 1930 a net income of $\$ 3522.71$; sustaining memberships for the year amounted to $\$ 3,335.00$. The amount received from sales of the Society's publications was $\$ 7,609.37$. During the year the special contributions from members to the amount of $\$ 1,110.25$ were received, which prevented a deficit on this year's business. The trustees adopted a budget for 1931 showing estimated expenditures and receipts as $\$ 38,006.77$; and $\$ 37,111.77$, respectively.

The Librarian reported that the Library of the Society now contains 8,133 volumes.

The following appointments were reported: to represent the Society at the Centennial Celebration of the founding of Randolph-Macon College, October 24, 1930, Professor J. J. Luck; to represent the Society at the Seventy-Fif th Anniversary of the founding of the Pennsylvania State College, October 24, 1930, Dr. Willis Whited; as representative on the National Research Council for the period ending June 30, 1933, and to replace Professor R. G. D. Richardson resigned, Professor D. R. Curtiss; as tellers at the annual election of officers, Professor C. R. Adams, Dr. A. A. Albert, and Professor P. A. Smith.

It was announced that Professor J. F. Ritt had accepted the invitation to give the Los Angeles Colloquium and that his subject is Systems of algebraic differential equations.

At the meeting of the Council the following appointments were authorized and announced: as an additional member of the committee on increasing the funds of the Society, Professor W. D. Cairns; as the nominating committee, Professors Virgil Snyder (chairman), L. L. Dines, H. J. Ettlinger, H. H. Mitchell, and H. L. Rietz; as the committee on the Award of the Cole 
Prize, Professors L. E. Dickson (chairman), H. F. Blichfeldt, and D. N. Lehmer; as the committee on nomination of the Gibbs Lecturer for 1932, Professors R. E. Langer (chairman), W. R. Longley, and F. D. Murnaghan; as the committee on arrangements for the annual meeting of 1931, Professors H. E. Buchanan (chairman), G. C. Evans, W. L. Miser, R. G. D. Richardson, and W. P. Webber; as representative to the committee on notation of the American Institute of Electrical Engineers, Professor E. V. Huntington; as representative on the National Research Council to succeed Professor Julian Coolidge, Professor E. R. Hedrick; as representatives on the Council of the American Association for the Advancement of Science, Professors Louis Ingold and M. H. Ingraham.

A resolution of appreciation of the work of Professor Dresden, who has served the Society for fifteen years in the secretarial capacity was passed by the Council and also at the annual meeting of the Society. It was announced that Professor R. L. Moore had accepted the visiting lectureship for the academic year 1931-32 and that arrangements would be made for these lectures during March and April of 1932. It was announced that Associate Secretary Mark H. Ingraham will be in charge of the preliminary arrangements for these lectures, and that institutions desiring to have Professor Moore visit them on this lecture tour should notify Professor Ingraham as soon as possible.

Future meetings of the Society were fixed as follows: New York City, February 28, April 3-4, October 31; Minneapolis, September 8-10; New Orleans, December 28-31; Berkeley, April 11. A meeting of the Society has already been arranged for April 3-4 in Chicago.

The Ninth Josiah Willard Gibbs Lecture will be given in New Orleans by Professor P. W. Bridgeman of Harvard University. The papers whose titles appear below were read in six sections. President Hedrick presided at the section on Analysis on Tuesday morning; Professors E. P. Lane and A. B. Coble at the section on Geometry; Professor E. T. Bell at the section on Algebra. On Wednesday morning President Hedrick and Professor Birkhoff presided at the section on Analysis; Professor Solomon Lefschetz at the section on Point Sets and Dr. T. C. Fry at the section on Probabilities. Mr. Jesse Price was intro- 
duced by Professor J. A. Nyswander, Professor Stetson by Professor E. W. Chittenden, Mr. Martin by Professor A. D. Michal, Professor Geronimus by Professor M. H. Ingraham, Dr. Seidel by Professor J. L. Walsh, Dr. Starcher by Professor R. D. Carmichael, Mr. Oldenberger by Professor L. M. Graves, Dr. Schoenberg by Professor G. A. Bliss, Mr. Bohnenblust by Professor Einar Hille, Dr. Cauer by Professor Norbert Wiener, Mr. Craig by Professor H. L. Rietz, and Mr. Evelyn and Dr. Linfoot by Professor Oswald Veblen. The papers whose abstract numbers are followed by the letter $t$ were read by title.

\section{Section I, Analysis, Tuesday Morning.}

1. Solutions of differential equations in the neighborhood of singular points, by Mr. Jesse Pierce. (Abstract No. 37-1-37.)

2. Note on the Green's function of a star-shaped three dimensional region, by Dr. J. J. Gergen. (Abstract No. 37-1-26.)

3. Necessary and sufficient conditions for the representation of a function as a Laplace integral, by Professor D. V. Widder. (Abstract No. 37-1-34.)

4. Generalization to three dimensions of the Cauchy integral formula, by Professor G. Y. Rainich. (Abstract No. 37-1-57.)

5. A new type of Cauchy integral, by Professor G. C. Evans. (Abstract No. 37-1-70.)

6. On double orthogonal series, by Dr. R. P. Agnew. (Abstract No. 37-1-29.)

7. On the trigonometric expansion of elliptic functions, by Professor M. A. Basoco. (Abstract No. 37-1-38.)

8. Lebesgue derivatives, by Professor J. S. Taylor. (Abstract No. 37-1-59.)

9. Closure of the set of translations of a function, by Professor Norbert Wiener. (Abstract No. 37-1-87.)

10. On double function space, by Professor H. E. Stelson. (Abstract No. 37-1-102.)

11. Some general theorems on composition of singularities, by Dr. W. J. Trjitzinsky. (Abstract No. 37-1-71-t.)

12. Small oscillations of the neutral helium atom near the equilateral triangle positions, by Professor H. E. Buchanan. (Abstract No. 36-11-431.)

13. On the Fourier series expansions of certain Jacobian elliptic functions, by Professor M. A. Basoco. (Abstract No. 37-1-40-t.)

14. On certain theta constants, by Professor M. A. Basoco. (Abstract No. 37-1-39-t.) 
15. Systems of linear integral equations with applications to an invariantive theory of quadratic functional forms in $n$ functions, by Dr. T. S. Peterson. (Abstract No. 37-1-55-t.)

16. One-parameter linear functional groups in several functions of two variables, by Professor A. D. Michal. (Abstract No. 37$1-62-$ t.)

17. The introduction of Stieltjes integrals in the transformation theory of functional forms, by Professor Michal and Mr. R. S. Martin. (Abstract No. 37-1-63-t.)

18. Note on functional forms quadratic in a function and its first $p$ derivatives, by Mr. R.S. Martin. (Abstract No.37-1-64-t.)

19. Isogonal trajectories in space, by Professor Edward Kasner. (Abstract No. 37-1-65-t.)

20. The analogue of periodicity for general Fourier series, by Professor R. E. Gilman. (Abstract No. 37-1-68-t.)

21. On orthogonal polynomials, by Professor J. Geronimus. (Abstract No. 37-1-72-t.)

22. The existence of rational functions of best approximation, by Professor J. L. Walsh. (Abstract No. 37-1-74-t.)

23. Solution of the problem of Plateau for three contours, by Professor Jesse Douglas. (Abstract No. 37-1-83-t.)

24. Proof of a surmisal of Hilbert concerning a role of the Dirichlet principle in analysis, by Professor Jesse Douglas. (Abstract No. 37-1-84-t.)

25. Minimax and instability configurations of a soap film bounded by two contours, by Professor Jesse Douglas. (Abstract No. 37-1-85-t.)

26. Example of a Jordan curve in space in which no finite area can be spanned, by Professor Jesse Douglas. (Abstract No. 37-1-86-t.)

27. On hypergeometric functions of two variables, by Dr. T. H. Rawles. (Abstract No. 37-1-90-t.)

28. Linear differential equations whose coefficients are of bounded variation, by Mr. L. J. Paradiso. (Abstract No. 37-189-t.)

29. On the cluster values of Schlicht and bounded analytic functions, by Dr. W. Seidel. (Abstract No. 37-1-92-t.)

30. On the correspondence of boundaries in conformal maps, by Dr. W. Seidel. (Abstract No. 37-1-93-t.)

31. Oscillation of sequences and functions, by Professor W. A. Hurwitz. (Abstract No. 37-1-103-t.) 


\section{Section II, Geometry, Tuesday Morning.}

32. Concerning the possibility of certain binary quartics being line sections of the plane quartic curve of genus zero and the complete system of independent forms of two binary quartics, by Professor J. H. Neelley. (Abstract No. 37-1-42.)

33. The bitangential curve, by Professor T. R. Hollcroft. (Abstract No. 36-11-403.)

34. Complete sets of tensors and invariants of systems of linear homogeneous differential equations of the second order, by Professor C. M. Cramlet. (Abstract No. 37-1-82.)

35. A system of circles, associated with a comformal transformation, by Professor Tobias Dantzig. (Abstract No. 37-1-78.)

36. The transformation $E$ of nets, by Professor V. G. Grove. (Abstract No. 36-11-412.)

37. Plane cubic Cremona transformations with coincident fundamental points, by Professor H. C. Shaub. (Abstract No. 371-50.)

38. Construction of pencils of equianharmonic cubics, by Dr. Jacob Yerushalmy. (Abstract No. 37-1-61.)

39. Groups of motions in spaces with distant parallelism, by Professor H. P. Robertson. (Abstract No. 37-1-51.)

40. On linear connections, by Dr. J. H. C. Whitehead. (Abstract No. 37-1-73-t.)

41. Multivectorial curvature, by Professor M. S. Knebelman. (Abstract No. 37-1-31-t.)

42. Near-collineations and Blaschke's Textilemathematik, by Professor Edward Kasner. (Abstract No. 37-1-66-t.)

43. Continuous curves which are homogeneous except for a countable infinity of points, by Dr. T. C. Benton. (Abstract No. 37-1-66-t.)

\section{Section III, Algebra and Number Theory, Tuesday Morning.}

44. On identities arising from solutions of q-difference equations and some interpretations in number theory, by Dr. G. W. Starcher. (Abstract No. 37-1-27.)

45. The regularity of genus of positive ternary quadratic forms, by Professor B. W. Jones. (Abstract No. 37-1-38.)

46. The class numbers of real cyclotomic fields. by Professor C. G. Latimer. (Abstract No. 37-1-45.)

47. Certain universal functions of generalized polygonal numbers, by Professor L. W. Griffiths. (Abstract No. 36-11-425.) 
48. Ideal multiplication in a rational linear associative algebra, by Miss Grace Shover and Professor C. C. MacDuffee. (Abstract No. 36-11-424.)

49. Tactical configurations of rank two, by Professor R. D. Carmichael. (Abstract No. 36-9-384-t.)

50. Algebras of certain doubly transitive groups, by Professor R. D. Carmichael. (Abstract No. 36-9-383.)

51. The degree of simply transitive primitive substitution groups of class $u$, by Professor Marie J. Weiss. (Abstract No. 37-1-46.)

52. Reduction of linear transformations to canonical forms, by Mr. W. O. Menge. (Abstract No. 37-1-52.)

53. On the Hadamard determinant theorem and orthogonal determinants, by Professor R. E. Gilman. (Abstract No. 37-1-68.)

54. Compositions of $n$-way matrices and multilinear forms, by Mr. Rufus Oldenburger. (Abstract No. 37-1-44.)

55. On the Wedderburn norm condition for cyclic algebras, by Dr. A. A. Albert. (Abstract No. 36-11-417-t.)

56. Note on Diophantine automorphisms, by Dr. Leonard Carlitz, National Research Fellow. (Abstract No. 37-1-48-t.)

57. Numerical functions in the ring of polynomials, mod p., by Dr. Leonard Carlitz. (Abstract No. 37-1-49-t.)

58. Parametric solutions of certain Diophantine equations, by Professor T. A. Pierce. (Abstract No. 37-1-67-t.)

59. A composition of determinants, by Professor Arnold Dresden. (Abstract No. 37-1-79-t.)

\section{Section IV, Analysis, Wednesday Morning.}

60. A new theory of parametric problems in the calculus of variations, by Professor F. L. Wren. (Abstract No. 36-11-428.)

61. Note on variation problems with prescribed transversality coefficients and extremals, by Professor Lincoln LaPaz. (Abstract No. 37-1-76.)

62. On the problem of Lagrange, by Professor L. M. Graves. (Abstract No. 36-11-422.)

63. Discontinuous solutions for the anormal case of the Lagrange problem in the calculus of variations, by Professor Gillie A. Larew. (Abstract No. 36-11-432.)

64. On boundary value problems associated with double integrals in the calculus of variations, by Dr. W. T. Reid. (Abstract No. 37-1-56.)

65. On the interchange of limit and Lebesgue integral for a se- 
quence of functions, by Professor T. H. Hildebrandt. (Abstract No. 37-1-30.)

66. Solution of bounded variation of a functional equation, by Mr. L. J. Paradiso. (Abstract No. 37-1-89.)

67. The minimizing properties of geodesic arcs with conjugate end points, by Dr. I. Schoenberg, International Research Fellow. (Abstract No. 37-1-94.)

68. On the absolute convergence problem for Dirichlet's series, by Mr. H. F. Bohnenblust and Professor Einar Hille. (Abstract No. 37-1-91-t.)

69. On the absolute convergence problem for Dirichlet's series, II, by Mr. H. F. Bohnenblust and Professor Einar Hille. (Abstract No. 37-1-95.)

70. Two theorems on the partitions of numbers, by Professor W. B. Ford. (Abstract No. 37-1-104-t.)

71. Electrical networks and bounded functions, by Dr. W. Cauer. (Abstract No. 37-3-114-t.)

72. A transformation of the problems of Lagrange, by Professor L. M. Graves. (Abstract No. 36-11-423-t.)

73. A reduction of sufficient conditions in the fixed end point problem of Lagrange, by Professor Marston Morse. (Abstract No. 37-1-88-t.)

\section{Section V, Theory of Point Sets, Wednesday Morning.}

74. Biconnected and related sets, by Dr. P. M. Swingle. (Abstract No. 37-1-54.)

75. On conical accessibility in $E_{3}$ (three-dimensional euclidean space), by Dr. T. C. Benton. (Abstract No. 37-1-80.)

76. Spaces in which there exist consecutive points, by Professor R. L. Moore. (Abstract No. 37-1-32.)

77. Concerning the sum of a monotonic increasing sequence of continuous curves, by Professor G. T. Whyburn. (Abstract No. 37-1-77-t.)

78. Concerning the structure of perfect continuous curves, by Professor G. T. Whyburn. (Abstract No. 37-1-99.)

79. A plane, arcwise connected and connected im kleinen set which is not strongly connected im kleinen, by Professor R. L. Wilder. (Abstract No. 36-11-418.)

80. The Poincaré duality theorem for topological manifolds, by Dr. W. W. Flexner. (Abstract No. 37-1-75.) 
81. On a problem of $N$. Aronszajn and an axiom of $R$. L. Moore, by Dr. Leo Zippin. (Abstract No. 37-1-36-t.)

82. Cyclicly connected continuous curves and correspondences, by Dr. V. W. Adkisson. (Abstract No. 37-1-41-t.)

83. Concerning locally connected spaces, by Professor G. T. Whyburn. (Abstract No. 37-1-58-t.)

84. On the relative cyclic-element decomposition of subcontinua of a continuous curve, by Professor G. T. Whyburn. (Abstract No. 37-1-97-t.)

85. Concerning the "closed components" of the non-regular parts of a continuum, by Professor G. T. Whyburn. (Abstract No. 37-1-98-t.)

86. On the cyclic and higher connectivity of locally connected spaces, by Professor G.T. Whyburn. (Abstract No. 37-1-100-t.)

87. A c-point connected continuous curve containing no uncountable collection of mutually exclusive continua, by Professor G. T. Whyburn. (Abstract No. 37-1-101-t.)

\section{Section VI, Theory of Probability and Other Topics, Wednes- day Morning.}

88. A method of classification for the distributions obtained in small samples, by Professor E. G. Olds. (Abstract No.37-1-33.)

89. On the distribution of certain statistics obtained from small random samples, by Mr. A. T. Craig. (Abstract No. 37-1-53.)

90. Distribution of the correlation coefficient in small samples from non-normal universes, by Professor P. R. Rider. (Abstract No. 37-1-35.)

91. A new definition of a Stieltjes integral, by Professor A. H. Copeland. (Abstract No. 37-1-43.)

92. Euler-Maclaurin summation formula for two variables by use of Bernoulli polynomials in two variables, by Dr. W. D. Baten. (Abstract No. 37-1-47.)

93. Matrices of integers ordering derivatives, by Professor J. M. Thomas. (Abstract No. 36-11-421.)

94. Apparent variables from the standpoint of combinatory logic, by Professor H. B. Curry. (Abstract No. 37-1-60.)

95. On a problem in the additive theory of numbers, by $\mathrm{Mr}$. C. J. A. Evelyn and Dr. E. H. Linfoot. (Abstract No. 371-96-t.)

M. H. Ingraham, Associate Secretary 